\title{
FTIR and Raman Spectroscopy Study of Soot Deposits Produced in the Infrared Multiphoton Dissociation of Vinyl Bromide
}

\author{
B. Samoudi $\left(\mathbb{D},{ }^{1,2}\right.$ O. Bendaou $\mathbb{D}^{2},{ }^{2}$ I. Hanafi $\left(\mathbb{D},{ }^{1}\right.$ A. Asselman $\mathbb{D}^{2},{ }^{2}$ and K. Haboubi $\mathbb{D D}^{1}$ \\ ${ }^{1}$ Civil Engineering,Energetic and Environment Department, National School of Applied Sciences of Al-Hoceima, \\ Abdelmalek Essaâdi University, Sidi Bouafif, Ajdir- Al-Hoceima 32003, B.P. 03, Morocco \\ ${ }^{2}$ Optics and Photonics Team, Faculty of Sciences, Abdelmalek Essâadi University, B.P.2121, M'Hannech II, \\ 93030 Tétouan, Morocco \\ Correspondence should be addressed to B.Samoudi; b.samoudi@uae.ac.ma
}

Received 29 March 2021; Revised 30 November 2021; Accepted 20 January 2022; Published 25 February 2022

Academic Editor: Luciano Bachmann

Copyright (C) 2022 B. Samoudi et al. This is an open access article distributed under the Creative Commons Attribution License, which permits unrestricted use, distribution, and reproduction in any medium, provided the original work is properly cited.

\begin{abstract}
Even at low concentrations, poly-aromatic hydrocarbons found in soot have substantial health implications. Soot deposits have been reported and studied using FTIR and Raman spectroscopy. Using a $\mathrm{CO}_{2}$ photolysis laser, the samples were obtained via infrared multiphoton dissociation (IRMPD) of vinyl bromide $\left(\mathrm{VBr}, \mathrm{C}_{2} \mathrm{H}_{3} \mathrm{Br}\right.$ ) molecules. The solid deposit formed in the IRMPD of $\mathrm{VBr}$ when a relatively high fluence of the order of $204 \mathrm{~J} . \mathrm{cm}^{-2}$ was analyzed by FTIR, and it was discovered that the majority of its composition is aromatic and aliphatic hydrocarbons. Significant fullerene-type carbonaceous soot particles are also found, which could correspond to $\mathrm{C}_{60}$ and $\mathrm{C}_{70}$ or other carbonaceous agglomerates of a higher order; however, the disappearance of this fullerene on Raman spectra cast doubt on this explanation. Our samples' Raman spectroscopy has been compared to Tamor and Vassell's research, which may indicate that they have a lesser degree of hardness and density than these authors' results, indicating a larger hydrogen content in our samples. The optical gap has been calculated, yielding a very limited range of values ranging only between 1.0 and $1.2 \mathrm{eV}$, resulting in a crystalline size of 0.58 to $1.12 \mathrm{~nm}$.
\end{abstract}

\section{Introduction}

Soot, also known as black carbon, is a significant substance produced by the incomplete combustion of hydrocarbons, with a large body of research devoted to its generation, characterization, characteristics, and effects on the environment and human health [1]. Soot can be found in the atmosphere, oceans, soil, sediments, and ice sheets, among other places [2]. In terms of climate change, current estimates imply that black carbon, after $\mathrm{CO}_{2}$, is the second most significant contributor to global warming [1]. From a health aspect, black carbon particles have been shown to have negative impacts on human health and have a considerable impact on human life expectancy [3-6]. Vehicle motors [7], biomass burners [8], and hydrocarbon fuels [9] are only a few of the many sources of soot.

Understanding the morphological and chemical properties of soot is critical for improving particle soot emission reduction techniques. Spectroscopy (i.e., Raman spectroscopy $[10-12$, Fourier-transform infrared spectroscopy [12-14], UV-vis spectroscopy $[15,16], \mathrm{X}$-ray photoelectron spectroscopy $[12,17,18]$, and electron energy loss spectroscopy $[19,20])$ is often used to characterize the chemical features of soot, while the microscopy (i.e., scanning probe microscopy [21-23], transmission electron microscopy with high resolution [20, 24], transmission electron microscopy with high resolution [25-27], SEM [28, 29], and helium ion microscopy $[30,31])$ is used for morphological properties studies. Microscopy creates pictures of the spatial distribution of density, composition, or morphology, whereas spectroscopy determines the chemical composition and physical structures of soot. The most appropriate approach is determined by the parameter of interest and the stage of soot production in question.

Soot samples collected from flames and combustion have been characterized in previous studies. They looked through 
a guideline for choosing between several microscopy and spectroscopic techniques for analyzing the characteristics of soot at various phases of its development (incipient, young, and mature soot). However, depending on the combination of investigated attributes, amount of soot maturity, and characterization approach is chosen, accuracy, quantification, and time and cost may differ [32].

Recent investigations were conducted to resolve the chemical and physical aspects of soot categorized by aerodynamic diameter using Raman spectroscopy and TEM analysis [11]. From the tiny to the big aerodynamic diameter, the Raman spectra revealed a constant change. The total (unclassified) soot samples produced by an inverted burner employing ethylene burning in bottled air have spectra that are comparable to the middle stages, which makes sense given that the middle stages capture the majority of the aerosol mass. The Raman spectra are fitted to a five-band model in decreasing ratios as the size increases. This indicates that the bigger particles have more organized graphitic domains and are larger.

Popovicheva et al. presented an intriguing study [8] to examine the environmental implications of generated soot at various fuel mixtures and operation circumstances. The scientists used microscopic methods such as scanning electron microscopy and high-resolution TEM analysis, Raman, and FTIR spectroscopic characterization to examine the soot of those particles [8]. Primary particles, such as fullerenic nuclei, are agglomerated and surrounded by a graphitic layer in this study. In addition, when the heating value of the fuel combination grew, the ratio of disordered to ordered carbon dropped.

Kazemimanesh et al. [9] published another study that used the same characterization methodologies to describe the morphological, physical, and nanostructure soot particles generated by a buoyant turbulent diffusion flame. The scientists found that when the fuel mix varied from light to medium to heavy, the particle median diameter and concentration rose. The morphological characterization was also unaffected by fuel type, flow rate, or flare size. The $D_{1} / G$ ratio of soot particles dropped as the fuel mixture composition varied from light to heavy, showing that heavier fuels had higher graphitic material.

Other research employing Raman spectroscopy and TEM analysis looks at the size and shape of soot formed from a big, buoyant turbulent diffusion flame situated at the size of soot from gas flares as a function of fuel and water addition. Fuels with a higher HHVv form bigger aggregates in greater amounts on average than fuels with a lower $\mathrm{HHVv}$, suggesting a graphitic structure [33].

Several studies showing the positive impact on the environment and potential benefits of soot aerosols as a reinforcing agent in the polymer and automotive industries. A method for making feasible multifunctional nanocomposites with carbon-based, metallic, or ceramic nanoparticles or nanofibers that considers both wettability and conductivity in the air has been reported [34]. Similarly, a recent review paper [35] investigated for the first time-optimal approaches for postsynthesis reuse of carbonaceous aerosols to develop superhydrophobic coatings for various industrial uses. Furthermore, the focus of this research has shifted to recyclability procedures and the practical implications of any sort of soot that is extremely water-repellent.

To our knowledge, no deposits of soot have been documented as a result of the infrared multiphoton dissociation (IRMPD) procedure of vinyl bromide. The goal of this investigation is to see if FTIR and Raman spectroscopy can be used to investigate the black soot created during the VBr IRMPD process. First, we will go through the results of IR spectroscopy on soot deposition. To determine the physical parameters of our samples, we compared them to data gathered from Tamor and Vassell's earlier work [36].

\section{Materials and Methods}

2.1. IRMPD Process Using a $\mathrm{CO}_{2}$ Photolysis Laser. IRMPD is an important process in physics and chemistry, in addition to being an elementary process of radiation-matter interaction. The energy of the electromagnetic field absorbed by the molecule in the ground state through an active mode is transformed into its internal energy, and if this energy exceeds the vibrational potential barrier, overcoming the anharmonicity of molecules, dissociation or photofragmentation can occur [37]. After irradiating a vibrational absorption band with a suitably powerful pulsed laser beam, this procedure is simple; however, several (10 to 40) infrared photons are required in most circumstances [38]. Although large levels of vibrational excitation can be seen in both the generated species and the parent molecule, this energy is usually insufficient to fill higher electronic states of photofragments [39]. However, electronic excitation of the products can occur in some situations, resulting in UV or visible emission. Unlike the IRMPD process, ultraviolet multiphoton dissociation occurs primarily in the excited electronic state, with the absorption of 1 to 3 photons causing electronic transitions that lead to molecular photodissociation [40].

IRMPD in polyatomic molecules is one of the more widespread approaches for initiating unimolecular reactions from the ground state and acquiring free radicals and fragments of interest in kinetic investigations [38]. In the high-temperature chemistry of hydrocarbons, elementary processes involving tiny carbon species such as $\mathrm{C}_{2}$ and $\mathrm{C}_{3}$ play an essential role, as shown in the production and decay of the newly found $\mathrm{C}_{60}$ fullerene $[41,42] . \mathrm{C}_{2}$ is created by IRMPD of a range of polyatomic compounds [43, 44], and vinyl halides are one of them $[45,46]$, using easy laser-induced chemistry. IRMPD of $\mathrm{VBr}$ using the $10 \mathrm{P}(24)$ line of a TEA $\mathrm{CO}_{2}$ laser has previously produced $\mathrm{C}_{2} \mathrm{H}_{2}, \mathrm{HBr}$, and noncondensable gas, thought to be hydrogen, as final stable products $[39,47]$. When a sharply concentrated beam was utilized, generally with a $10 \mathrm{~cm}$ focal length lens, more $\mathrm{C}_{4} \mathrm{H}_{2}$ and black carbon soot was produced. In each experiment, the $24 \mathrm{~cm}$ lens produced no solid products. Another paper [40] provided a time-resolved analysis of the IR fluorescence emissions caused by IRMPD of VBr under various experimental settings. Three species have been investigated: the 
parent $\mathrm{VBr}$, the generated $\mathrm{HBr}^{\dagger}$, and $\mathrm{C}_{2} \mathrm{H}_{2}{ }^{\dagger}$, where ${ }^{\dagger}$ is the vibrational energy [39].

Figure 1 shows the experimental setup used for the IRMPD procedure of the $\mathrm{VBr}$ samples, which has been largely detailed in earlier publications [39, 47]. Only a basic explanation of the experimental setup will be offered in this section. The $\mathrm{CO}_{2}$ photolysis laser is a Lumonics model K-101 transverse excitation atmospheric (TEA) laser with frontal Ge multimode optics (35\% reflection) and a 135 lines $/ \mathrm{mm}$ rear diffraction grating blazed at $10.6 \mu \mathrm{m}$. The irradiation is done with the $10 \mathrm{P}(24)$ line at $940.56 \mathrm{~cm}^{-1}$, which is roughly resonant with the $\mathrm{VBr}$ molecule's $\nu_{5}$ torsion mode. A 16-A spectrum analyzer is used to examine the wavelength (Optical Eng. Co.). In all of studies, the ratio of $\mathrm{CO}_{2}: \mathrm{N}_{2}: \mathrm{He}$ was set to 8:8:84. The temporal form of the TEA- $\mathrm{CO}_{2}$ laser pulse in this setting (see Figure 1) was a pronounced spike of full width at half maximum (FWHM) 64 ns followed by a long-lasting tail of lower energy, which was tracked shot by shot with a Rofin Sinar 7415 photon drag detector. A Lumonics $20 \mathrm{D}$ with an area of $18 \mathrm{~cm}^{2}$ and an energy detection threshold of $5 \mathrm{~mJ}$ was used to monitor the $\mathrm{CO}_{2}$ laser's energy in front of the lens. The pyrometer's calibration error is $5 \%$, and the fluctuation of its response on the surface is a maximum of $5 \%$ when it comes to the one in the center. A pyroelectric array detector Delta Development Mark IV, which consists of a linear array of 60 pyroelectric detectors with a total length of $26.2 \mathrm{~mm}$ and a resolution of $0.4375 \mathrm{~mm}$, was used to measure the focused radius of the laser beam at the target point. $(7.50 .6) \times 10^{-3} \mathrm{~cm}^{2}$ was the measured focused-spot area. The greatest laser energy observed was $(1,530 \pm 76) \mathrm{mJ}$, resulting in fluence of $(204 \pm 6)$ $\mathrm{J} . \mathrm{cm}^{-2}$.

2.2. FTIR Spectroscopy. The absorption of IR photons by molecules is the basis of infrared (IR) spectroscopy. The process of absorption can occur when the energy of the IR photon to be absorbed corresponds with the difference in energy between two levels of molecule rovibrational energy. The frequency-domain spectrum of the resultant interferogram is then Fourier transformed, giving birth to the term Fourier-transform infrared (FTIR) spectroscopy [48].

An infrared spectrophotometer, Perkin-Elmer model 1725X, was used to record FTIR transmission spectra in all experiments. This device uses a ceramic incandescent source that is heated to $1400^{\circ} \mathrm{C}$. A DTGS (deuterated triglycine sulfate with quick recovery) detector with a cesium iodide window was used. The beam splitter is made of $\mathrm{KBr}$ and is multicoated. It spans the spectrum range of $400 \mathrm{~cm}^{-1}$ to $10,000 \mathrm{~cm}^{-1}$, yet it is only practical up to $600 \mathrm{~cm}^{-1}$ in these instances owing to the $\mathrm{NaCl}$ optics' transmittance. The spectral resolution was $2 \mathrm{~cm}^{-1}$, and each sample yielded 100 scans, resulting in an excellent signal-to-noise ratio. There was no substantial absorption over $4,000 \mathrm{~cm}^{-1}$ in any of the experiments.

The traditional $\mathrm{KBr}$ pellet approach is used in this FTIR investigation. Both the samples and the $\mathrm{KBr}$ were dried in a vacuum before analysis to reduce the influence of moisture on the spectra. The transmission signal associated with the clean $\mathrm{KBr}$ pellet was removed from each spectrum to get the spectrum of the simple.

2.3. Raman Spectroscopy. Raman scattering has long been acknowledged as a potent spectroscopic tool for determining the degree of structural organization of carbonaceous matter, whether it is a natural substance or an organic material that has been intentionally generated (graphitized) in experimental settings [36, 49-56]. Carbon-carbon bonding may occur in a variety of ways to produce molecular and crystalline structures, which is exceptional when compared to other elements in the periodic table.

Carbon films, both amorphous and nanocrystalline, may exist in a variety of matrices and are frequently doped with a considerable quantity of hydrogen, making the materials even more complex. Hybridizations of $\mathrm{sp}^{3}$ and $\mathrm{sp}^{2}$ are the most prevalent chemical linkages in amorphous and nanocrystalline carbon. A carbon atom in the $\mathrm{sp}^{3}$ configuration produces four $\mathrm{sp}^{3}$ orbitals, forming a strong connection with the next atom [57]. Some Raman spectral features of several forms of amorphous carbon have been linked to deposition circumstances and macroscopic qualities [58-60].

Tamor and Vassell investigated a variety of amorphous carbonaceous materials from various sources and manufactured them using various procedures [36]. They correlated the adjustment parameters with the physical attributes of the samples, such as hydrogen concentration, optical gap, hardness, and density, by fitting the Raman spectra to two types of Gaussian lines. The analysis of this database indicates several relationships that may be utilized to predict the qualities of other films. Furthermore, despite their phenomenological character, these correlations appear to apply to all amorphous carbon films and hence may be beneficial to all carbonaceous material researchers.

A Renishaw inVia Raman equipment with an electrically cooled CCD camera and a Leica DM 2500 microscope was used to detect the Raman spectra. The equipment was fitted with laser sources, allowing it to be used. As an excitation source, a diode laser (HPNIR 785 model, Renishaw) with a wavelength of $785 \mathrm{~nm}$ was utilized, producing power of $2 \mathrm{~mW}$. Raman scattering was filtered with a holographic notch filter system to minimize Rayleigh's elastic dispersion of photons with appropriate diffraction grids and then captured with a $400 \times 575$ pixel electrically air-cooled CCD detector. ${ }^{-}$Two wavenumber was chosen as the resolution. Without any additional preparation, samples placed on glass and put into $\mathrm{VBr}$ photolysis cells were examined immediately. Each time, a $10 \mathrm{~s}$ scan was taken.

All of the Raman spectra were fitted with two Gaussians to determine the locations and intensities of the $G$ and $D$ peaks. The criteria we employ here are the same as those applied elsewhere [36]: the breadth of a Gaussian curve, $\sigma$. The FWHM (full width at half maximum) is around $2.30 \sigma$. Because it gives good fits for all the soot deposits, these two Gaussian fits properly duplicate the data and more complicated line shape functions. This might be backed up by scientific evidence. 


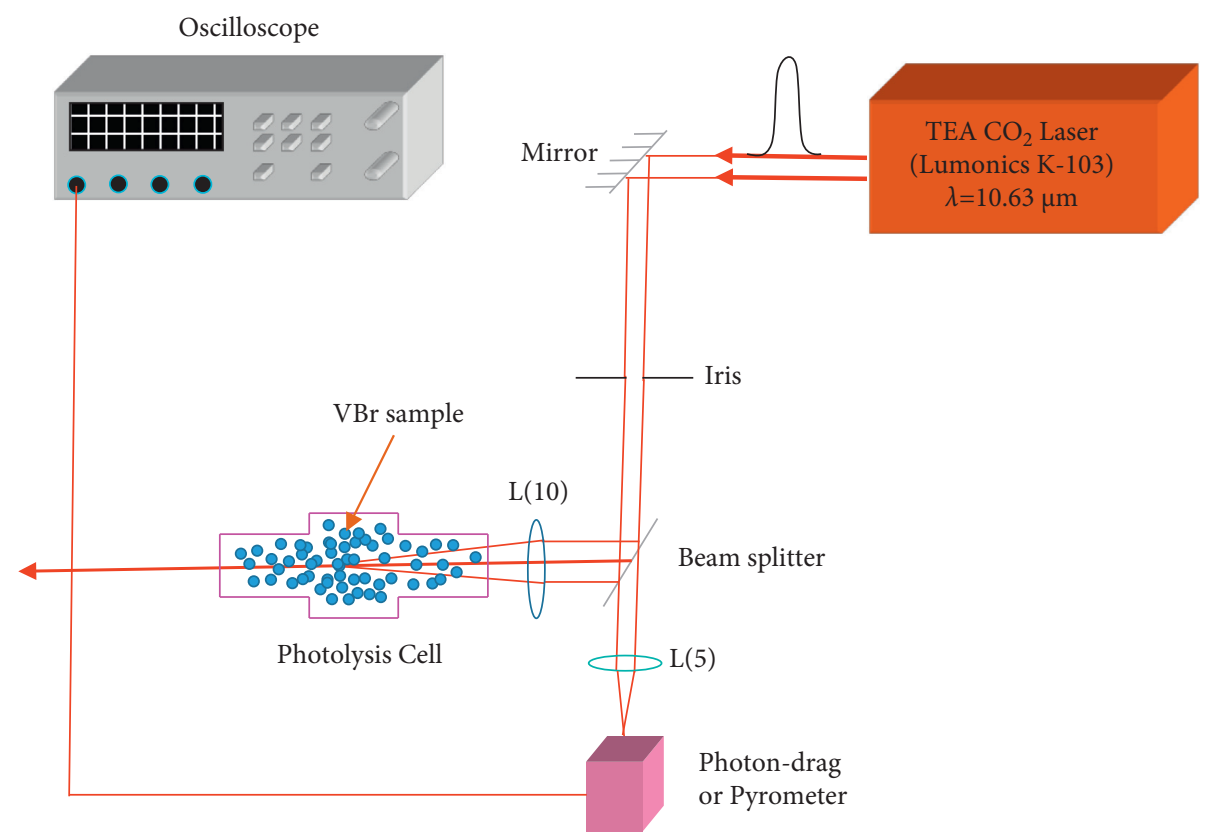

FIGURE 1: Experimental arrangements employed for the IRMPD of the VBr samples for inducing black soot.

The acquired spectra should be deconvoluted to identify the precise placements, bandwidths, and relative intensities. The Raman spectra were processed using the built-in peak fitting analysis capabilities in OriginPro 7.5 software (OriginLab Corporation, USA).

\section{Results and Discussion}

3.1. FTIR Spectroscopy Study of the Soot Deposits. Figure 2 shows the $2.5 \mathrm{hPa}$ FTIR spectrum of a BrV pure simple in a gaseous state, recorded between $600 \mathrm{~cm}^{-1}$ and $4,000 \mathrm{~cm}^{-1}$ before and after being bombarded with more than 600 infrared pulses (Figures 2(a) and 2(b)), respectively. Along with the decrease in the bands belonging to the $\mathrm{BrV}$, additional bands appear with the original spectrum, showing that the BrV has decoupled, as can be seen in the spectrum obtained after the irradiation. The bands at $730 \mathrm{~cm}^{-1}$ and $3,270 \mathrm{~cm}^{-1}$, attributed to the torsional vibrations of the $\mathrm{CH}$ bond of the five modes and the three asymmetric $\mathrm{CH}$ stretch modes, respectively, have been recognized as belonging to acetylene $\left(\mathrm{C}_{2} \mathrm{H}_{2}\right)$ [61-63].

The transitions of vibrationally excited hydrogen bromide $\mathrm{HBr}(1-3)$ have been attributed to the bands occurring between $2,400 \mathrm{~cm}^{-1}$ and $2,700 \mathrm{~cm}^{-1}[61,62,64]$. Furthermore, a solid deposit has been seen clinging to the cell walls and windows. Bands at $1,065 \mathrm{~cm}^{-1}$ and $1,165 \mathrm{~cm}^{-1}$ may be found in Figure 2(b) of this deposit. There are no solid deposits when a small fluence is utilized. Table 1 summarizes the detection of gaseous end products and the characterization of soot deposits.

Lussier and Steinfeld [65] achieved similar results in the IRMPD of vinyl chloride under identical circumstances to ours. They identify stable end products $\mathrm{C}_{2} \mathrm{H}_{2}, \mathrm{HCl}, \mathrm{C}_{4} \mathrm{H}_{2}, \mathrm{H}_{2}$, and a solid deposit when the laser energy is highly concentrated in this situation. When the sample is irradiated
TABLE 1: Identification of products obtained from IRMPD of VBr.

\begin{tabular}{lccc}
\hline Sample & Technique used & Products & Bands $\left(\mathrm{cm}^{-1}\right)$ \\
\hline \multirow{3}{*}{$\mathrm{VBr}$} & FTIR & $\mathrm{C}_{2} \mathrm{H}_{2}$ & $730,3,270$ \\
& FTIR & $\mathrm{HBr}$ & $2,400-2,700$ \\
& FTIR & $\mathrm{C}_{2} \mathrm{H}_{4}$ & 3,329 \\
\multirow{3}{*}{ Soot deposits } & FTIR & $\mathrm{H}_{2}$ & - \\
& FTIR & Solid deposit & $1,065,1,165$ \\
& FTIR & $\mathrm{C}_{60}$ & 527 \\
& FTIR & $\mathrm{C}_{70}$ & $795,1,134,1,460$ \\
\hline
\end{tabular}

with a reduced fluence, the only products generated are $\mathrm{C}_{2} \mathrm{H}_{2}$ and $\mathrm{HCl}$, according to Lussier's team. Figure 3 shows the FTIR spectrum of a deposit solid that was observed clinging to cell walls and windows. The vibrational transitions of numerous bonds present in the structure create peaks in the IR spectra. Table 2 shows some typical band locations in poly-aromatic hydrocarbon molecules and soot $[8,13,14,32,66]$ due to certain chemical functionalities. At various frequencies, the spectrum reveals multiple unique absorption peaks. Because of the amount of material combined into the pellet, the bands in the figure have a substantial intensity. The absorption peaks in this spectrum (Figure 3) correspond to the $\mathrm{C}-\mathrm{H}$ aliphatic functional groups and have wavenumbers of $2,850 \mathrm{~cm}^{-1}, 2,925 \mathrm{~cm}^{-1}$, and $2,960 \mathrm{~cm}^{-1}$. The peak corresponding to the wavenumber $2,925 \mathrm{~cm}^{-1}$ is the most intense of these peaks. Similar behavior has been documented in previous soot experiments $[13,14,66-68]$. The spectrum also presents many absorption peaks at $1,390 \mathrm{~cm}^{-1}$ and $1,460 \mathrm{~cm}^{-1}$, showing the presence of a $\mathrm{C}-\mathrm{H}$ aliphatic bond, which is caused by scissoring and bending deformation in $\mathrm{CH}_{3}$ and $\mathrm{CH}_{2}[13,14]$. The peak origin at $1,600 \mathrm{~cm}^{-1}$ could be due to aromatic $\mathrm{C}=\mathrm{C}$ functionalities. Literature $[13,32]$ attributes the $1,720 \mathrm{~cm}^{-1}$ wavenumber range to the carbonyl $\mathrm{C}=\mathrm{O}$ stretch. A large 


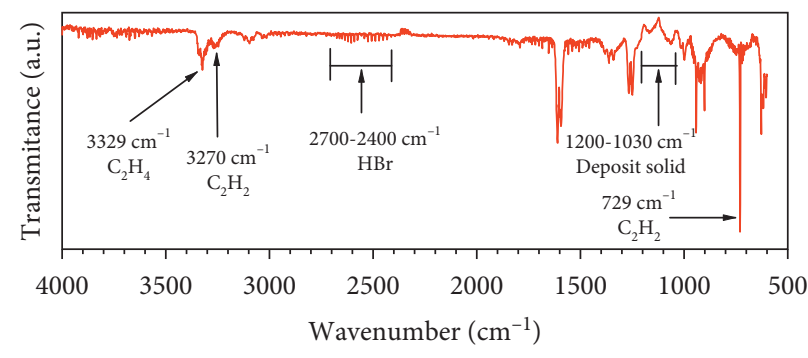

(a)

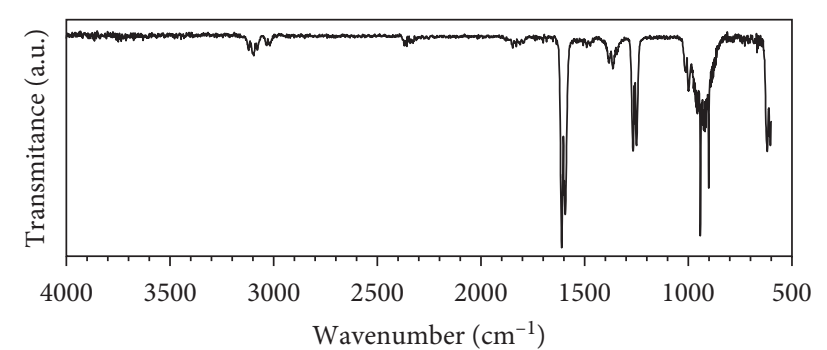

(b)

FIgUre 2: (a) FTIR spectrum of a $2.5 \mathrm{hPa}$ of $\mathrm{VBr}$ pure sample in a gaseous state, recorded between $600 \mathrm{~cm}^{-1}$ and $4,000 \mathrm{~cm}^{-1}$. (b) FTIR spectrum after being irradiated with more than 600 infrared pulses.

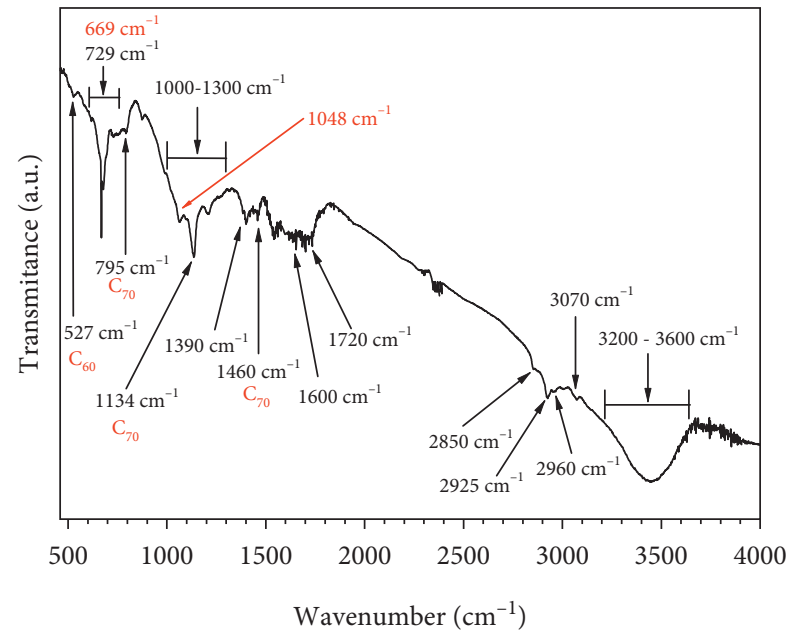

FIGURE 3: FTIR spectrum of soot deposits obtained in the IRMPD of $2.5 \mathrm{hPa}$ of $\mathrm{VBr}$.

vibration band in the range of $3,200-3,600 \mathrm{~cm}^{-1}$ is also visible in the FTIR spectra [68]. The stretching vibration of the $\mathrm{OH}$ - functional group present in the sample is responsible for the peak $\left(3,435 \mathrm{~cm}^{-1}\right)$ at this position. The existence of this peak, on the other hand, may be attributable to a water molecule absorbed by the $\mathrm{KBr}$ salt during sample preparation or spectral acquisition. The existence of tiny $\left(\mathrm{sp}^{2}\right.$ or $\mathrm{sp}^{3}$ ) aromatic clusters of amorphous carbon soot is indicated by certain weak bands found at low wavenumbers $1,048 \mathrm{~cm}^{-1}$ and $669 \mathrm{~cm}^{-1}$ [69].

We can also see some weak bands and shoulders, which we believe are caused by $\mathrm{C}_{60}$ and $\mathrm{C}_{70}$ fullerenes [70] or higher-order carbonaceous agglomerates. This identification was made feasible by comparing the spectra of the soot deposits to that of a fullerene combination synthesized at the Rocasolano Institute of Physical Chemistry (Madrid, Spain) and illustrated in Figure 4. Previously, fullerene-type carbonaceous structures were discovered in pyrolysis experiments using IR lasers pulsed in acetylene, ethene, and benzene [71-73]. These findings show that the high temperatures obtained in pulsed IR pyrolysis $(>2,000 \mathrm{~K})$ promote the production of curved carbonaceous structures that can evolve into fullerenes, rather than the more prevalent flat graphene sheets generated at lower temperatures $(1,500 \mathrm{~K}-1,800 \mathrm{~K})$.
We conducted multiple tests with Raman spectroscopy analysis to gain a better understanding of the generation of fullerene in the IRMPD process. The absence of $\mathrm{C}_{60}$ and $\mathrm{C}_{70}$ fullerenes in our samples' Raman spectra cast doubt on this explanation.

3.2. Raman Spectroscopy Study of the Soot Deposits. The Raman spectra of all solid deposits obtained from the IRMPD of $\mathrm{VBr}$ include the characteristic two primary features: the $\mathrm{G}$ band at $1,550 \mathrm{~cm}^{-1}$ and the $\mathrm{D}$ band at around $1,350 \mathrm{~cm}^{-1}$ (Figure 5). The physical origins of these two Raman modes are described in detail in $[9,74]$ : the $\mathrm{sp}^{2}$ sites are responsible for the $G$ and $D$ peaks. The bond stretching of all pairings of $\mathrm{sp}^{2}$ atoms in both rings and chains causes the $\mathrm{G}$ peak. The $\mathrm{D}$ peak is caused by defects along graphitic edge planes and is caused by the breathing modes of $\mathrm{sp}^{2}$ atoms in rings. There have been no bands observed in the second-order region of the spectrum, between $2,000 \mathrm{~cm}^{-1}$ and $3,600 \mathrm{~cm}^{-1}$, which is dominated by a modulated bump formed of overtone and combination bands [75], nor around $600 \mathrm{~cm}^{-1}$, where broadband has been detected in hydrogenfree carbon films $[68,76]$. We get values for the G band and its associated breadth that are comparable to those reported by various studies $[10,36,74,75,77]$, even though they are concentrated in the higher frequency area. These findings, together with the lack of a band at $600 \mathrm{~cm}^{-1}$, indicate that our deposits are hydrogenated. Our results for the D band, on the other hand, show a lower frequency location than those reported by these writers. It is worth noting that their Raman spectra were obtained using an argon laser at $514.5 \mathrm{~nm}$, whereas ours were obtained using a diode laser at $785 \mathrm{~nm}$. We validated that the identical spectra are produced at $785 \mathrm{~nm}$ using an argon laser at $514.5 \mathrm{~nm}$; however, in the first case, a significantly stronger fluorescence background emerges, for which we offer the data obtained at $785 \mathrm{~nm}$. The parameters obtained for our samples, including the results of these authors for the hydrogenated samples, are shown in Figures 6(a) and 6(b).

Tamor and Vassell [36] discovered relationships between the width of the $\mathrm{G}$ band and macroscopic deposit characteristics including hardness and density. We will be able to compare our results with theirs and estimate the hardness, density, and optical gap of our samples since the placements of the G band in our samples, as well as their associated 
TABLE 2: IR absorption wavenumber of soot and polyaromatic hydrocarbons summarized from the literature $[8,13,14,66]$.

\begin{tabular}{lc}
\hline Main peak wavenumber $\left(\mathrm{cm}^{-1}\right)$ & Chemical functional group to which assigned $\left(\mathrm{cm}^{-1}\right)$ \\
\hline $1,000-700$ & Aromatic $\mathrm{C}=\mathrm{C}-\mathrm{H}$ out of plane deformation \\
$1,300-1,000$ & Aromatic $\mathrm{C}-\mathrm{C}$ and $\mathrm{C}-\mathrm{H}$ plane deformation and ether $\mathrm{C}-\mathrm{O}-\mathrm{C}$ stretching \\
1,460 & Aromatic $\mathrm{C}=\mathrm{C}$ stretching \\
1,600 & Aliphatic $\mathrm{C}-\mathrm{H}$ bending and scissoring of $\mathrm{CH}_{3}$ and $\mathrm{CH}_{2}$ \\
1,720 & Aromatic $\mathrm{C}=\mathrm{C}$ stretching \\
$2,850,2,925$, and 2,960 & Carbonyl $\mathrm{C}=\mathrm{O}$ stretching \\
3,039 & Asymmetric and symmetric $\mathrm{C}-\mathrm{H}$ stretching of $\mathrm{CH}_{3}$ and $\mathrm{CH}_{2}$ aliphatic functional groups \\
3,435 & Aromatic compounds $\mathrm{C}=\mathrm{C}-\mathrm{H}$ stretching \\
$3,000-3,600$ & Water $\mathrm{O}-\mathrm{H}$ stretch \\
& Hydroxyl $\mathrm{O}=\mathrm{H}$ group \\
\hline
\end{tabular}

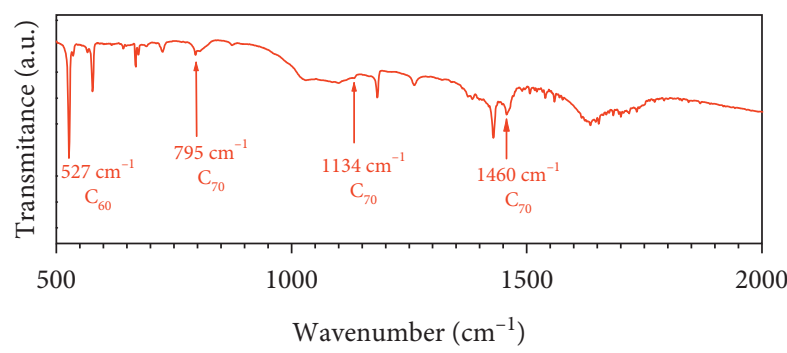

(a)

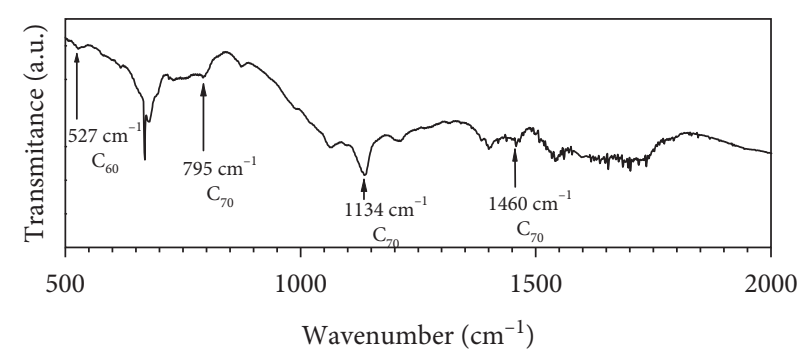

(b)

Figure 4: (a) Spectrum of the soot deposits formed after irradiating a $10 \mathrm{hPa}$ of $\mathrm{VBr}$ pure sample with the $\mathrm{CO}_{2}$ laser. $\varphi=204 \mathrm{~J} \cdot \mathrm{cm}^{-2}$. (b) Spectrum of a synthetic fullerene sample.

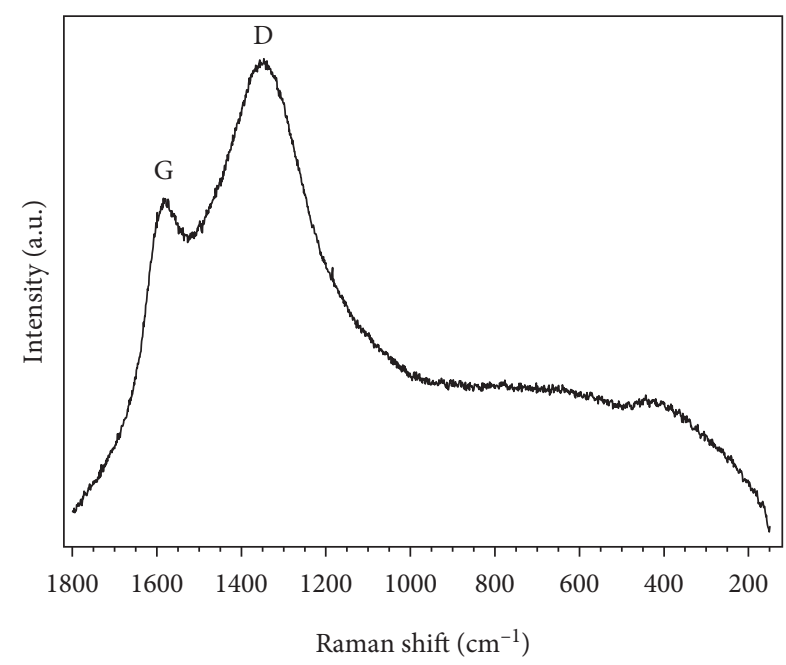

Figure 5: Typical Raman spectra of the soot deposits obtained in the IRMPD process of $\mathrm{VBr}$.

widths, are comparable to those acquired by these authors. Figures $7(\mathrm{a})-7(\mathrm{c})$ show the findings obtained.

Hardness is the most important attribute for protective coatings in tribological applications. The resistance to the penetration of a hard counterbody is defined by the ratio of applied force to the indentation area. The peak position shift of $\mathrm{G}$ band is associated with an increase in $\mathrm{sp}^{3}$ concentration for an a-C:H and an increase in hardness, according to Ferrari and Robertson [74]. In addition, a rise in the full width at half maximum (FWHM) of G band suggests a decrease in the in-plane correlation length $\left(L_{a}\right.$, commented later) and an increase in carbon disorder, both of which are signs of the nucleation of tiny $\mathrm{sp}^{3}$ sites formed from $\mathrm{sp}^{2}$ bonds [74].

As can be observed, our samples had a lesser degree of hardness (i.e., up to $7 \mathrm{GPa}$ ) and density (i.e., ranging between $1.4 \mathrm{~g} . \mathrm{cm}^{-3}$ and $2.0 \mathrm{~g} . \mathrm{cm}^{-3}$ ) than the ones tested by Tamor and Vassell [36], which might indicate a larger hydrogen concentration in our samples based on their findings.

The optical gap has been estimated (Figure $7(\mathrm{c})$ ), obtaining a very narrow range of values varying only between $1.0 \mathrm{eV}$ and $1.2 \mathrm{eV}$. So the lower bandgap can be interpreted; as the overall hydrogen content decreases, the $\pi$-bonded clusters increase in size and modify their shape. The dependence of the optical gap on the hydrogen content is explained by invoking a more pronounced $\mathrm{sp}^{2}$ character in the less-hydrogenated films. Hence, higher hydrogen contents are associated with larger gaps. In this trend, many studies of hydrogenated diamond-like carbon comparable with our gap values (i.e., 1.0-2.0 eV) using a Raman spectroscopy estimated an $\mathrm{H}$ content (20\%-40\%) and confirm this purpose $[78,79]$.

The maximum intensities ratio $\left(I_{\mathrm{D}} / I_{\mathrm{G}}\right)$ has long been used as a useful indicator of crystal structure disorder in soot samples, and it is related to lattice width $\left(L_{a}\right)$. Tuinstra and Koenig [56] were the first to show a linear connection between the relationship of intensities given by the areas of bands $\mathrm{D}$ and $\mathrm{G}, I_{\mathrm{D}} / I_{\mathrm{G}}$, of the Raman spectra and the effective crystallite size, $L_{a}$, in the graphite plane direction. The proportionality constant is dependent on the wavelength laser, $L_{a}$, employed to acquire the Raman spectra [80-82]. 


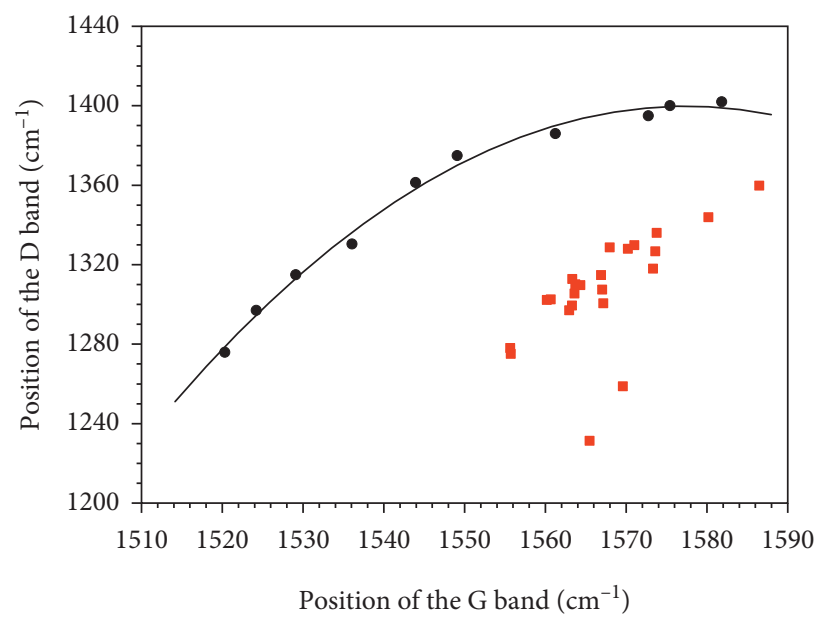

(a)

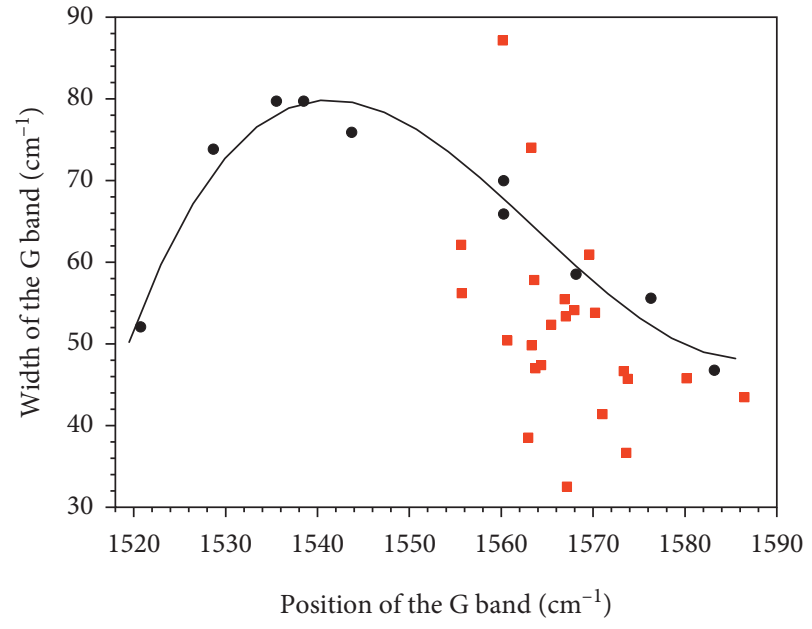

(b)

Figure 6: (a) Position of D band versus position of G band. (b) G bandwidth versus G band position; $\mathbf{n}$, this work; $\bullet$, work from Tamor and Vassell [36].

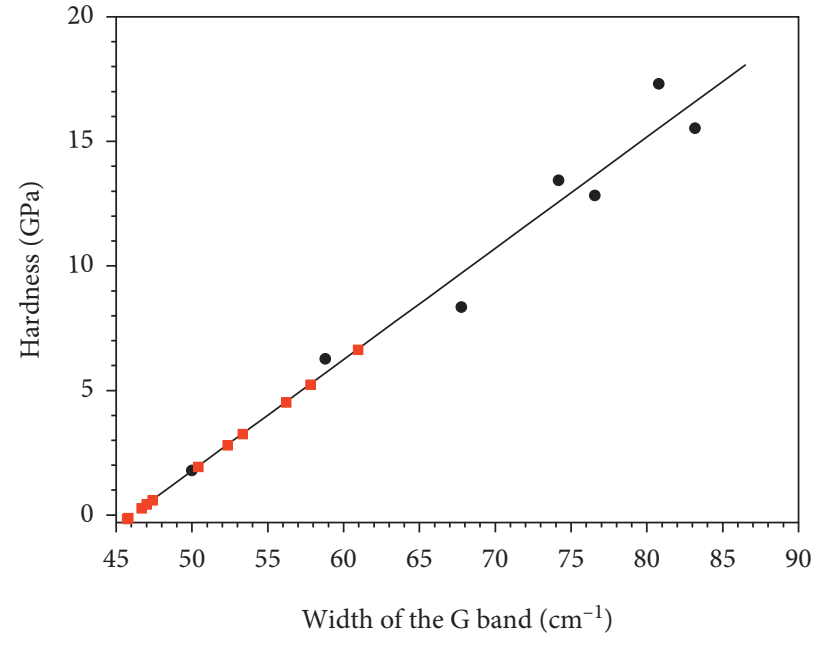

(a)

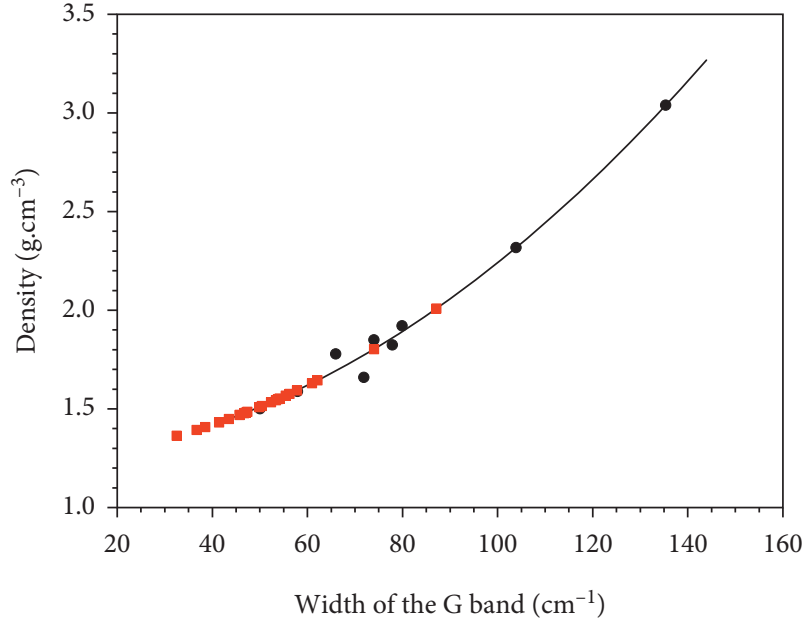

(b)

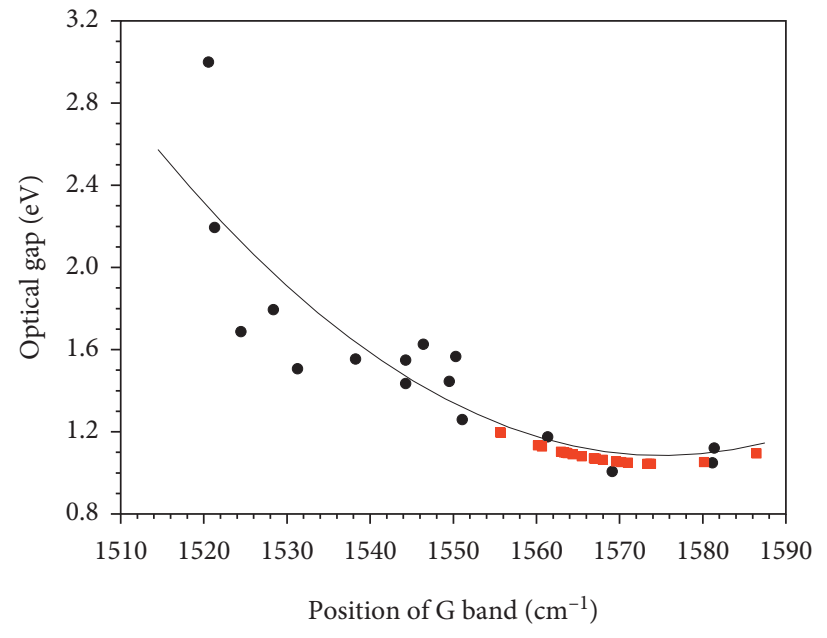

(c)

Figure 7: (a) Hardness of soot deposits as a function of G bandwidth. (b) Density of soot deposits as a function of G bandwidth. (c) Optical gap of soot deposits as a function of the Raman G band position; $\mathbf{m}$, this work; $\bullet$, work from Tamor and Vassell [36]. 


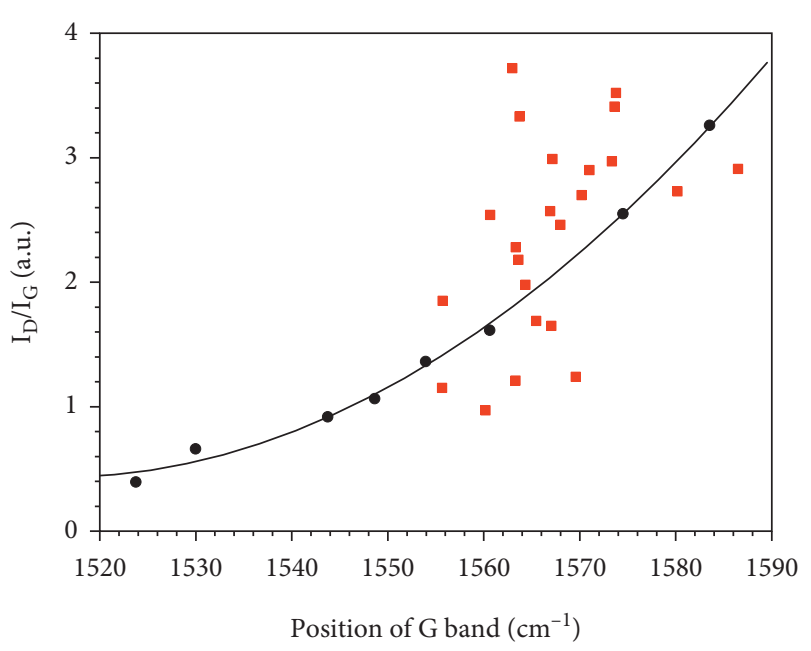

FIgURE 8: The ratio of the integrated areas of the Raman D and G bands $\left(I_{\mathrm{D}} / I_{\mathrm{G}}\right)$ as a function of the $\mathrm{G}$ band position; $\boldsymbol{n}$, this work; $\bullet$, work from Tamor and Vassell [36].

This dependency is linear in the range $400 \mathrm{~nm}<\lambda_{L}<700 \mathrm{~nm}$. Various phrases have been given in the literature to estimate $L_{a}$ as follows:

$$
L_{a}^{2}(\mathrm{~nm})=B(\lambda) \cdot\left(\frac{I_{\mathrm{D}}}{I_{\mathrm{G}}}\right),
$$

with $B(\lambda)=1.82$ for laser excitation energy, $E_{l}=2.41 \mathrm{eV}$, used in Raman experiment has been proposed by Ferrari and Robertson [83]. Cançado et al. [84] utilized a generic equation to demonstrate $\left(I_{\mathrm{D}} / I_{\mathrm{G}}\right) . E_{L}^{4}$ is proportional to $1 / L_{a}$ when using Raman spectroscopy to determine the crystallite size $L_{a}$ of nanographite. Other research $[20,74,75,84]$ has lately provided a clear explanation for this pattern. The ratio between the integrated intensities of the disorder-induced $\mathrm{D}$ and $\mathrm{G}$ Raman bands, $I_{\mathrm{D}} / I_{\mathrm{G}}$, in nanographite samples with different crystallite sizes $L_{a}$ and using different excitation laser energies has been studied in detail, resulting in a general equation for determining $L_{a}$ using any visible laser energy. These results reveal that $I_{\mathrm{D}} / I_{\mathrm{G}}$ is inversely proportional to the fourth power of the laser energy utilized in the experiment, indicating that the linearity in the visible region is confirmed. Our samples' $I_{\mathrm{D}} / I_{\mathrm{G}}$ values (Figure 8 ) are in the range of 1.0 to 3.7 . If we use the known proportionality constant for excitation laser wavelengths of $785 \mathrm{~nm}$ as an example, the crystalline size, $L_{a}$, for them varies between $0.58 \mathrm{~nm}$ and $1.12 \mathrm{~nm}$, depending on the following formula $[75,85]$ :

$$
L_{a}^{2}\left(\mathrm{~nm}^{2}\right)=5 \cdot 4 \cdot 10^{-2} \cdot E_{l}^{4}\left(\mathrm{eV}^{4}\right) \cdot\left(\frac{I_{\mathrm{D}}}{I_{\mathrm{G}}}\right) .
$$

\section{Conclusions}

A new approach for soot formation by IRMPD of VBr was applied in this study while applying a rather high fluence of the order of $204 \mathrm{~J} . \mathrm{cm}^{-2}$. FTIR and Raman's spectroscopy have been used to characterize such goods. FTIR spectroscopy was used to examine the soot deposits formed in the IRMPD of VBr when a relatively high fluence of the order of $204 \mathrm{~J} . \mathrm{cm}^{-2}$ was used. It was discovered that the majority of the soot particles were the aliphatic and aromatic groups. On the other hand, we had also found some indication that the deposited soot is fullerene-type carbonaceous soot, which could correspond to $\mathrm{C}_{60}$ and $\mathrm{C}_{70}$ or other carbonaceous agglomerates of a higher order; however, the tests realization by Raman spectroscopy make in doubt this purpose. When employing Raman spectroscopy, we discovered that they had a lesser degree of hardness and density than the samples analyzed by Tamor and Vassell, which might indicate a larger hydrogen content in our samples, based on their findings. The optical gap has been calculated, yielding a very restricted range of values ranging only between $1.0 \mathrm{eV}$ and $1.2 \mathrm{eV}$, resulting in a crystalline size of $0.58 \mathrm{~nm}$ to $1.12 \mathrm{~nm}$ for them.

\section{Data Availability}

No data were used to support this study.

\section{Conflicts of Interest}

The authors declare that they have no conflicts of interest.

\section{Acknowledgments}

The authors would like to thank Dr. Santiago SanchezCortès (the Surface Spectroscopies and Surface Plasmon Photonics Group Laboratory, CSIC Madrid) who provided them free access to the Raman instrument. This work was granted by PHC Maghreb (Program Hubert Curien) MELINA (Mastering Efficient Lighting in North Africa) and supported by Campus France and, in Morocco, by the Ministry of Higher Education, Scientific Research and Innovation, in partnership with the National Center for Scientific and Technical Research (CNRST).

\section{References}

[1] T. C. Bond, S. J. Doherty, D. W. Fahey et al., "Bounding the role of black carbon in the climate system: a scientific assessment," Journal of Geophysical Research: Atmospheres, vol. 118, no. 11, pp. 5380-5552, 2013.

[2] Encyclopedia of Atmospheric Sciences, Elsevier, Amsterdam, Netherlands, 2021, https://www.elsevier.com/books/ encyclopedia-of-atmospheric-sciences/north/978-0-12382225-3, 2nd edition.

[3] M. C. Power, M. G. Weisskopf, S. E. Alexeeff, B. A. Coull, A. Spiro, and J. Schwartz, "Traffic-related air pollution and cognitive function in a cohort of older men," Environmental Health Perspectives, vol. 119, no. 5, pp. 682-687, 2011.

[4] T. J. Luben, J. L. Nichols, S. J. Dutton et al., "A systematic review of cardiovascular emergency department visits, hospital admissions and mortality associated with ambient black carbon," Environment International, vol. 107, pp. 154-162, 2017.

[5] X. Chen, S. Kang, and J. Yang, "Investigation of distribution, transportation, and impact factors of atmospheric black carbon in the Arctic region based on a regional climate- 
chemistry model," Environmental Pollution, vol. 257, Article ID 113127, 2020.

[6] Z. Lu, D. G. Streets, E. Winijkul et al., "Light absorption properties and radiative effects of primary organic aerosol emissions," Environmental Science \& Technology, vol. 49, no. 8, pp. 4868-4877, 2015.

[7] N. Palazzo, L. Zigan, F. J. T. Huber, and S. Will, "Impact of oxygenated additives on soot properties during diesel combustion," Energies, vol. 14, no. 1, p. 147, 2021.

[8] O. Popovicheva, M. Timofeev, N. Persiantseva et al., "Microstructure and chemical composition of particles from small-scale gas flaring," Aerosol and Air Quality Research, vol. 19, no. 10, pp. 2205-2221, 2019.

[9] M. Kazemimanesh, R. Dastanpour, A. Baldelli et al., "Size, effective density, morphology, and nano-structure of soot particles generated from buoyant turbulent diffusion flames," Journal of Aerosol Science, vol. 132, pp. 22-31, 2019.

[10] A. C. Ferrari and D. M. Basko, "Raman spectroscopy as a versatile tool for studying the properties of graphene," Nature Nanotechnology, vol. 8, no. 4, pp. 235-246, 2013.

[11] D. C. Doughty and S. C. Hill, "Raman spectra of atmospheric aerosol particles: clusters and time-series for a $22.5 \mathrm{hr}$ sampling period," Journal of Quantitative Spectroscopy and Radiative Transfer, vol. 248, 2020.

[12] M. Pan, C. Wu, W. Qian et al., "Impact of dimethoxymethanediesel fuel blends on the exhaust soot's evolutionary behavior," Fuel, vol. 309, Article ID 122221, 2022.

[13] B. Paul, A. Datta, A. Datta, and A. Saha, "A comparison of chemical structures of soot precursor nanoparticles from liquid fuel combustion in flames and engine," Journal of Nanoparticle Research, vol. 15, no. 4, Article ID 1550, 2013.

[14] B. Paul and A. Datta, "FTIR characterization of soot precursor nano-particles from different heights of an isooctane/air premixed flame," International Journal of Advances in Engineering Sciences and Applied Mathematics, vol. 6, no. 1-2, pp. 97-105, 2014.

[15] V. Gargiulo, M. Alfè, G. Di Blasio, and C. Beatrice, "Chemicophysical features of soot emitted from a dual-fuel ethanoldiesel system," Fuel, vol. 150, pp. 154-161, 2015.

[16] M. Commodo, A. D’Anna, G. De Falco, R. Larciprete, and P. Minutolo, "Illuminating the earliest stages of the soot formation by photoemission and Raman spectroscopy," Combustion and Flame, vol. 181, pp. 188-197, 2017.

[17] J. O. Müller, D. S. Su, U. Wild, and R. Schlögl, "Bulk and surface structural investigations of diesel engine soot and carbon black," Physical Chemistry Chemical Physics, vol. 9, no. 30, pp. 4018-4025, 2007.

[18] K. O. Johansson, F. El Gabaly, P. E. Schrader, M. F. Campbell, and H. A. Michelsen, "Evolution of maturity levels of the particle surface and bulk during soot growth and oxidation in a flame," Aerosol Science and Technology, vol. 51, no. 12, pp. 1333-1344, 2017.

[19] S. Lim, S. Lee, T. Ahn, and S. Park, "Measurement of organic carbon content during the growth of soot particles in propane normal and inverse diffusion flames using a multiwavelength light extinction method," Carbon, vol. 149, pp. 519-529, 2019.

[20] P. P. Morajkar, M. K. Abdrabou, A. V. Salkar, A. Raj, M. Elkadi, and D. H. Anjum, "Nanostructural disorder and reactivity comparison of flame soot and engine soot using diesel and jatropha biodiesel/diesel blend as fuels," Energy \& Fuels, vol. 34, no. 10, pp. 12960-12971, 2020.

[21] Y. Liu, C. Song, G. Lv, N. Chen, H. Zhou, and X. Jing, "Determination of the attractive force, adhesive force, adhesion energy and Hamaker constant of soot particles generated from a premixed methane/oxygen flame by AFM," Applied Surface Science, vol. 433, pp. 450-457, 2018.

[22] F. Schulz, M. Commodo, K. Kaiser et al., "Insights into incipient soot formation by atomic force microscopy," Proceedings of the Combustion Institute, vol. 37, no. 1, pp. 885-892, 2019.

[23] M. Commodo, K. Kaiser, G. De Falco et al., "On the early stages of soot formation: molecular structure elucidation by high-resolution atomic force microscopy," Combustion and Flame, vol. 205, pp. 154-164, 2019.

[24] B. Apicella, A. Tregrossi, A. Ciajolo, J. Abrahamson, R. L. Vander Wal, and C. Russo, "The effect of temperature on soot properties in premixed ethylene flames," Combustion Science and Technology, vol. 191, no. 9, pp. 1558-1570, 2019.

[25] Y. Jung and C. Bae, "Immaturity of soot particles in exhaust gas for low temperature diesel combustion in a direct injection compression ignition engine," Fuel, vol. 161, pp. 312-322, 2015.

[26] M. R. Kholghy, A. Veshkini, and M. J. Thomson, “The coreshell internal nanostructure of soot-a criterion to model soot maturity," Carbon, vol. 100, pp. 508-536, 2016.

[27] M. Kazemimanesh, A. Baldelli, U. Trivanovic et al., "Particulate emissions from turbulent diffusion flames with entrained droplets: a laboratory simulation of gas flaring emissions," Journal of Aerosol Science, vol. 157, Article ID 105807, 2021.

[28] H. Chu, W. Han, W. Cao, C. Tao, M. Raza, and L. Chen, "Experimental investigation of soot morphology and primary particle size along axial and radial direction of an ethylene diffusion flame via electron microscopy," Journal of the Energy Institute, vol. 92, no. 5, pp. 1294-1302, 2019.

[29] W. Han, Y. Ya, H. Chu, W. Cao, Y. Yan, and L. Chen, "Morphological evolution of soot emissions from a laminar co-flow methane diffusion flame with varying oxygen concentrations," Journal of the Energy Institute, vol. 93, no. 1, pp. 224-234, 2020.

[30] M. Schenk, N. Hansen, H. Vieker, A. Beyer, A. Gölzhäuser, and K. Kohse-Höinghaus, "PAH formation and soot morphology in flames of C4 fuels," Proceedings of the Combustion Institute, vol. 35, no. 2, pp. 1761-1769, 2015.

[31] C. Betrancourt, F. Liu, P. Desgroux et al., "Investigation of the size of the incandescent incipient soot particles in premixed sooting and nucleation flames of $n$-butane using LII, HIM, and $1 \mathrm{~nm}$-SMPS," Aerosol Science and Technology, vol. 51, no. 8, pp. 916-935, 2017.

[32] C. Russo, M. Pawlyta, A. E. Tomiczek, A. Ciajolo, and B. Apicella, "On the application of electron energy-loss spectroscopy for investigating nanostructure of soot from different fuels," Fuel, vol. 2, no. 3, pp. 367-375, 2021.

[33] U. Trivanovic, T. A. Sipkens, M. Kazemimanesh et al., "Morphology and size of soot from gas flares as a function of fuel and water addition," Fuel, vol. 279, Article ID 118478, 2020.

[34] V. S. Saji, "Carbon nanostructure-based superhydrophobic surfaces and coatings," Nanotechnology Reviews, vol. 10, no. 1, pp. 518-571, 2021.

[35] Y. Bai, H. Zhang, Y. Shao, H. Zhang, and J. Zhu, "Recent progresses of superhydrophobic coatings in different application fields: an overview," Coatings, vol. 11, no. 2, p. 116, 2021.

[36] M. A. Tamor and W. C. Vassell, "Raman "fingerprinting" of amorphous carbon films," Journal of Applied Physics, vol. 76, no. 6, pp. 3823-3830, 1994. 
[37] V. S. Letokhov, Laser Spectroscopy of Highly Vibrationally Excited Molecules, Adam Hilger, Bristol, UK, 1989.

[38] D. W. Lupo and M. Quack, "IR-laser photochemistry," Chemical Reviews, vol. 87, no. 1, pp. 181-216, 1987.

[39] L. Rubio, B. Samoudi, M. Santos, and L. Díaz, "Infrared fluorescence from multiphoton dissociation of vinyl bromide: emission from the products and the parent molecule," Journal of Photochemistry and Photobiology A: Chemistry, vol. 237, pp. 1-6, 2012.

[40] M. Castillejo, M. Martín, R. de Nalda, and J. Solís, "Nanosecond versus picosecond near UV multiphoton dissociation of ketene," Chemical Physics Letters, vol. 268, no. 5-6, pp. 465-470, 1997.

[41] S. C. O'Brien, J. R. Heath, R. F. Curl, and R. E. Smalley, "Photophysics of buckminsterfullerene and other carbon cluster ions," The Journal of Chemical Physics, vol. 88, no. 1, pp. 220-230, 1988.

[42] M. Ehbrecht, M. Faerber, F. Rohmund, and V. V. Smirnov, "C02-laser-driven production of carbon clusters and fullerenes from the gas phase," Chemical Physics Letters, vol. 5, 1993.

[43] R. Fantoni, E. Borsella, S. Piccirillo, A. Giardini-Guidoni, and R. Teghil, "IR photodecomposition of $\mathrm{CH}_{3} \mathrm{COCF}_{3}$ ", Laser Chemistry, vol. 8, no. 2-4, 24 pages, Article ID 904074 , 1988.

[44] Z. Li and J. S. Francisco, "Observation of the laser induced fluorescence spectra of $C_{2}\left(d^{3} \Pi_{\mathrm{g}} \leftarrow a^{3} \Pi_{\mathrm{u}}\right)$ from the infrared multiphoton dissociation of bis-trifluoromethyl peroxide," The Journal of Chemical Physics, vol. 96, no. 2, pp. 878-881, 1992.

[45] C. R. Quick and C. Wittig, "Infrared photodissociation of fluorinated ethanes and ethylenes: collisional effects in the multiple photon absorption process," The Journal of Chemical Physics, vol. 69, no. 9, pp. 4201-4205, 1978.

[46] F. M. Lussier, J. I. Steinfeld, and T. F. Deutsch, "Pressure and intensity dependence of multiphoton energy deposition and reaction yield in vinyl chloride," Chemical Physics Letters, vol. 58, no. 2, pp. 277-282, 1978.

[47] B. Samoudi, L. Díraz, M. Oujja, and M. Santos, "Real time study of the infrared multiphoton dissociation of vinylbromide," Journal of Photochemistry and Photobiology A: Chemistry, vol. 125, no. 1-3, pp. 1-11, 1999.

[48] S. A. Mahesar, M. Lucarini, A. Durazzo, A. Santini, A. I. Lampe, and J. Kiefer, "Application of infrared spectroscopy for functional compounds evaluation in olive oil: a current snapshot," Journal of Spectroscopy, vol. 2019, Article ID 5319024, 11 pages, 2019.

[49] C. Beny-Bassez and J. N. Rouzaud, "Characterization of carbonaceous materials by correlated electron and optical microscopy and Raman microspectroscopy," Scanning Electron Microscopy, vol. 1, pp. 119-132, 1985.

[50] D. González, M. A. Montes-Morán, I. Suárez-Ruiz, and A. B. Garcia, "Structural characterization of graphite materials prepared from anthracites of different characteristics: a comparative analysis," Energy \& Fuels, vol. 18, no. 2, pp. 365-370, 2004.

[51] A. Sadezky, H. Muckenhuber, H. Grothe, R. Niessner, and U. Pöschl, "Raman microspectroscopy of soot and related carbonaceous materials: spectral analysis and structural information," Carbon, vol. 43, no. 8, pp. 1731-1742, 2005.

[52] I. Suárez-Ruiz and A. B. García, "Optical parameters as a tool to study the microstructural evolution of carbonized anthracites during high-temperature treatment," Energy \& Fuels, vol. 21, no. 5, pp. 2935-2941, 2007.
[53] M. Marques, I. Suárez-Ruiz, D. Flores, A. Guedes, and S. Rodrigues, "Correlation between optical, chemical and micro-structural parameters of high-rank coals and graphite," International Journal of Coal Geology, vol. 77, no. 3-4, pp. 377-382, 2009.

[54] S. Potgieter-Vermaak, N. Maledi, N. Wagner, J. H. P. Van Heerden, R. Van Grieken, and J. H. Potgieter, "Raman spectroscopy for the analysis of coal: a review," Journal of Raman Spectroscopy, vol. 42, no. 2, pp. 123-129, 2011.

[55] X. He, X. Liu, B. Nie, and D. Song, "FTIR and Raman spectroscopy characterization of functional groups in various rank coals," Fuel, vol. 206, pp. 555-563, 2017.

[56] F. Tuinstra and J. L. Koenig, "Raman spectrum of graphite," The Journal of Chemical Physics, vol. 53, no. 3, pp. 1126-1130, 1970.

[57] P. K. Chu and L. Li, "Characterization of amorphous and nanocrystalline carbon films," Materials Chemistry and Physics, vol. 96, no. 2-3, pp. 253-277, 2006.

[58] M. Yoshikawa, G. Katagiri, H. Ishida, A. Ishitani, and T. Akamatsu, "Resonant Raman scattering of diamondlike amorphous carbon films," Applied Physics Letters, vol. 52, no. 19 , pp. 1639-1641, 1988.

[59] J. Wagner, M. Ramsteiner, C. Wild, and P. Koidl, "Resonant Raman scattering of amorphous carbon and polycrystalline diamond films," Physical Review B, vol. 40, no. 3, pp. 1817-1824, 1989.

[60] M. A. Tamor, J. A. Haire, C. H. Wu, and K. C. Hass, "Correlation of the optical gaps and Raman spectra of hydrogenated amorphous carbon films," Applied Physics Letters, vol. 54, no. 2, pp. 123-125, 1989.

[61] G. Herzberg, Molecular Spectra and Molecular Structures I. Spectra of Diatomic Molecules, Vol. I, D.Van Nostrand Company Inc., , New York City, NY, USA, 1950.

[62] D.-K. Liu, L. T. Letendre, and H.-L. Dai, "193 nm photolysis of vinyl bromide: nascent product distribution of the $\mathrm{C}_{2} \mathrm{H}_{3} \mathrm{Br} \longrightarrow \mathrm{C}_{2} \mathrm{H}_{2}$ (vinylidene) $+\mathrm{HBr}$ channel," The Journal of Chemical Physics, vol. 115, no. 4, pp. 1734-1741, 2001.

[63] K. K. Pushpa, A. Kumar, P. D. Naik, and A. V. Sapre, "UV/ visible luminescence from photo products in infrared multiphoton dissociation of acrylonitrile," Indian Journal of Chemistry, vol. 43A, no. 3, pp. 481-486, 2004.

[64] A. Carvalho, G. Hancock, and M. Saunders, "The reaction products of the $193 \mathrm{~nm}$ photolysis of vinyl bromide and vinyl chloride studied by time-resolved Fourier transform infrared emission spectroscopy," Physical Chemistry Chemical Physics, vol. 8, no. 37, pp. 4337-4346, 2006.

[65] F. M. Lussier and J. I. Steinfeld, "Multiple infrared photon dissociation of vinyl chloride," Chemical Physics Letters, vol. 50, no. 2, pp. 175-180, 1977.

[66] A. Santamaria, N. Yang, E. Eddings, and F. Mondragon, "Chemical and morphological characterization of soot and soot precursors generated in an inverse diffusion flame with aromatic and aliphatic fuels," Combustion and Flame, vol. 157, no. 1, pp. 33-42, 2010.

[67] J.-j. He, Q.-x. Hu, M.-n. Jiang, and Q.-x. Huang, "Nanostructure and reactivity of soot particles from open burning of household solid waste," Chemosphere, vol. 269, Article ID 129395, 2021.

[68] X. Liang, X. Lv, Y. Wang et al., "Experimental investigation of diesel soot oxidation reactivity along the exhaust aftertreatment system components," Fuel, vol. 302, Article ID 121047, 2021. 
[69] R. Tailor, Y. Kumar Vijay, and M. Bafna, "Carbon soot polymer nanocomposites (CSPNCs): production, surface morphological, glass transition temperature phenomenon and optical properties," in Environmental Emissions, R. Viskup, Ed., IntechOpen, London, UK, 2021.

[70] D. S. Bethune, G. Meijer, W. C. Tang et al., "Vibrational Raman and infrared spectra of chromatographically separated $\mathrm{C}_{60}$ and $\mathrm{C}_{70}$ fullerene clusters," Chemical Physics Letters, vol. 179, no. 1, pp. 181-186, 1991.

[71] M. Schnaiter, T. Henning, H. Mutschke, B. Kohn, M. Ehbrecht, and F. Huisken, "Infrared spectroscopy of nanosized carbon grains produced by laser pyrolysis of acetylene: analog materials for interstellar grains," The Astrophysical Journal, vol. 519, no. 2, pp. 687-696, 1999.

[72] V. Z. Mordkovich, "The observation of large concentric shell fullerenes and fullerene-like nanoparticles in laser pyrolysis carbon blacks," Chemistry of Materials, vol. 12, no. 9, pp. $2813-2818,2000$.

[73] I. Llamas-Jansa, C. Jäger, H. Mutschke, and T. Henning, "Farultraviolet to near-infrared optical properties of carbon nanoparticles produced by pulsed-laser pyrolysis of hydrocarbons and their relation with structural variations," Carbon, vol. 45, no. 7, pp. 1542-1557, 2007.

[74] A. C. Ferrari and J. Robertson, "Raman spectroscopy of amorphous, nanostructured, diamond-like carbon, and nanodiamond," Philosophical Transactions of The Royal Society A Mathematical Physical and Engineering Sciences, vol. 362, no. 1824, pp. 2477-2512, 2004.

[75] P. Minutolo, M. Commodo, A. Santamaria, G. De Falco, and A. D'Anna, "Characterization of flame-generated 2-D carbon nano-disks," Carbon, vol. 68, pp. 138-148, 2014.

[76] N. Wada, P. J. Gaczi, and S. A. Solin, “"Diamond-like” 3-fold coordinated amorphous carbon," Journal of Non-crystalline Solids, vol. 35-36, pp. 543-548, 1980.

[77] M. Commodo, A. E. Karataş, G. De Falco, P. Minutolo, A. D’Anna, and Ö. L. Gülder, "On the effect of pressure on soot nanostructure: a Raman spectroscopy investigation," Combustion and Flame, vol. 219, pp. 13-19, 2020.

[78] C. Casiraghi, F. Piazza, A. C. Ferrari, D. Grambole, and J. Robertson, "Bonding in hydrogenated diamond-like carbon by Raman spectroscopy," Diamond and Related Materials, vol. 14, no. 3-7, pp. 1098-1102, 2005.

[79] B. Schultrich, "Hydrogenated amorphous carbon films (a-C: $\mathrm{H})$," in Tetrahedrally Bonded Amorphous Carbon Films I, vol. 263, pp. 111-192, Springer Berlin Heidelberg, Berlin, Germany, 2018.

[80] A. V. Baranov, A. N. Bekhterev, Y. S. Bobovich, and V. I. Petrov, "Interpretation of certain characteristics in Raman spectra of graphite and glassy carbon," Optics and Spectroscopy, vol. 62, pp. 612-616, 1987.

[81] T. P. Mernagh, R. P. Cooney, and R. A. Johnson, "Raman spectra of Graphon carbon black," Carbon, vol. 22, no. 1, pp. 39-42, 1984.

[82] Y. Wang, D. C. Alsmeyer, and R. L. McCreery, "Raman spectroscopy of carbon materials: structural basis of observed spectra," Chemistry of Materials, vol. 2, no. 5, pp. 557-563, 1990.

[83] A. C. Ferrari and J. Robertson, "Interpretation of Raman spectra of disordered and amorphous carbon," Physical Review B, vol. 61, no. 20, pp. 14095-14107, 2000.

[84] L. G. Cançado, K. Takai, T. Enoki et al., "General equation for the determination of the crystallite size $L_{a}$ of nanographite by Raman spectroscopy," Applied Physics Letters, vol. 88, no. 16, Article ID 163106, 2006.
[85] L. G. Cançado, A. Jorio, E. H. Martins Ferreira et al., "Quantifying defects in graphene via Raman spectroscopy at different excitation energies," Nano Letters, vol. 11, no. 8, pp. 3190-3196, 2011. 